\title{
Vulvar basal cell carcinoma: A retrospective study of 29 cases from Queensland*
}

\author{
Ian S. C. Jones ${ }^{\#}$, Alex Crandon, Karen Sanday
}

Queensland Centre for Gynaecological Cancer, Royal Brisbane and Women’s Hospital, Brisbane, Australia

Email:

Received 17 April 2012; revised 19 May 2012; accepted 31 May 2012

\begin{abstract}
Objective: Review the clinical features, diagnosis, management and outcomes for 29 cases of Basal Cell Carcinoma (BCC) of the Vulva referred to Queensland Centre for Gynaecological Cancer (QCGC) between 1986 and 2010. Methods: Vulvar BCC cases from QCGC were reviewed and analysed using the computer software Statistical Package for the Social Sciences (SPSS) 11.0. Results: BCC of the vulva is uncommon with an incidence from the QCGC vulvar cancer registry of $3.2 \%$. Of the 29 patients one died of their BCC and seven died of unrelated causes. The mean age at diagnosis was 69.5 years (range 40 to 91). All cases were Caucasian. Time from onset of symptoms to diagnosis averaged 22.6 months (range 0 - 120 months). Not until a biopsy was performed was the diagnosis made. The most common presenting complaints were pruritis and a lump. Initial treatment was surgical. Conclusions: The prognosis for vulvar BCC is excellent. Histological diagnosis and long term follow-up are important management issues. The status of disease at the margins of surgical specimens does not reliably equate to patient long term outcomes. Follow up should be supervised via a gynecological oncology register to reduce the risk of patient loss to follow up.
\end{abstract}

Keywords: Vulvar Basal Cell Carcinoma; Diagnosis; Management; Outcome; Specimen Margins; Follow-Up

\section{INTRODUCTION}

Basal Cell Carcinoma (BCC) is the most common human malignancy accounting for $75 \%$ of all non-melanoma skin cancer [1] whereas vulvar BCC is an uncommon disease with incidence reports varying between $2 \%$ - 5\% of vulval malignancies [2,3].

"Conflict of interest statement: the authors declare that there are no conflicts of interest.

${ }^{\#}$ Corresponding author.
BCC's are categorized histologically as nodular, multifocal, superficial, cystic and infiltrative. In addition BCC's can have squamous differentiation and be associated with vulvar intra epithelial carcinoma (VIN). A detailed review of the histology of vulvar BCC is provided in Ridley's the Vulva (2009) [4].

\section{MATERIALS AND METHODS}

Records from the state wide Queensland Centre for Gynaecological Cancer (QCGC) data base for patients referred for registration and management of vulvar BCC between 1986 and 2010 together with their pathology reports were reviewed and analysed using the computer software Statistical Package for the Social Sciences (SPSS) 11.0.

Ethics approval for the review of case records was obtained from the Clinical Research Ethics Committee of the Royal Brisbane and Women's Hospital.

\section{RESULTS}

Twenty nine cases of vulval BCC were registered with QCGC and all were Caucasian. The number of cases registered each year ranged from zero to four. To date one case died of their BCC and seven died of other causes (Table 1). Their ages at diagnosis ranged from 40 to 91 years with a mean age at diagnosis of 69.5 years.

The time from the onset of symptoms to diagnosis varied considerably ranging from 1 week to over 10 years. In 2 cases the lesions were asymptomatic and were detected during routine examination. The most common presenting complaints were pruritis in 52\% and ulceration in $50 \%$ of cases. The site of BCC on the vulva was labia majora in eight cases (8/19 cases were the anatomical location could be determined) but the numbers were insufficient to make any reliable comment about a preferred site for vulvar BCC. There was no correlation between BCC histology and the anatomical location of the lesion (Table 2). The size of the BCC ranged in diameter from 0.4 to $5 \mathrm{~cm}$ (mean $2.1 \mathrm{~cm}$ ) and ulceration was present in $50 \%$ of cases. All cases underwent biopsy 
Table 1. BCC pathology group versus health status.

\begin{tabular}{|c|c|c|c|c|c|}
\hline \multirow{2}{*}{ Pathology Group } & \multicolumn{4}{|c|}{ Health Status } & \multirow{2}{*}{ Tota } \\
\hline & Alive & Dead of Disease & Dead of Other Disease & Lost to Follow Up & \\
\hline BCC & 4 & 1 & 2 & 1 & 8 \\
\hline Nodular & 5 & & & 1 & 6 \\
\hline Superficial & 4 & & & & 4 \\
\hline Solid + Infiltrative & & & 1 & & 1 \\
\hline Cystic & & & 1 & 1 & 2 \\
\hline Multifocal Superficial & 3 & & 1 & & 4 \\
\hline $\mathrm{BCC}+\mathrm{VIN}$ & 1 & & & & 1 \\
\hline BCC + Squamous Differentiation & 1 & & 1 & & 2 \\
\hline Solid + Cystic & & & 1 & & 1 \\
\hline Total & 18 & 1 & 7 & 3 & 29 \\
\hline
\end{tabular}

Table 2. Histological type versus location.

\begin{tabular}{|c|c|c|c|c|c|c|c|c|c|c|}
\hline \multirow{2}{*}{ Site } & \multicolumn{9}{|c|}{ BCC Histological Type } & \multirow{2}{*}{ Total } \\
\hline & BCC & Nodular & Superficial & $\begin{array}{c}\text { Solid } \\
+ \text { Infiltrative }\end{array}$ & Cystic & $\begin{array}{l}\text { Multifocal } \\
+ \text { Superficial }\end{array}$ & $\begin{array}{l}\text { BCC } \\
+ \text { VIN }\end{array}$ & $\begin{array}{l}\text { BCC + Squamous } \\
\text { Differentiation }\end{array}$ & $\begin{array}{l}\text { Solid } \\
+ \text { Cystic }\end{array}$ & \\
\hline Clitoris & & & & & & 1 & & & & 1 \\
\hline Lab min Left & & & & & & & 1 & & & 1 \\
\hline Lab min Right & & 1 & & & & & & & & 1 \\
\hline Lab maj Left & & 2 & & & & 1 & & & & 3 \\
\hline Lab maj Right & 1 & 1 & 2 & & 1 & & & & & 5 \\
\hline Perineum & 1 & & & & & & & & & 1 \\
\hline Left & 1 & & 1 & 1 & & 1 & & & & 4 \\
\hline Right & & 1 & 1 & & & & & 1 & & 3 \\
\hline Not Recorded & 5 & 1 & & & 1 & 1 & & 1 & 1 & 10 \\
\hline Total & 8 & 6 & 4 & 1 & 2 & 4 & 1 & 2 & 1 & 29 \\
\hline
\end{tabular}

for diagnosis followed by attempted excision of the lesions.

Surgical treatment was individualized and included local excision, wide local excision (WLE), hemi-vulvectomy, radical hemi-vulvectomy without groin dissection, one case of radical hemi-vulvectomy with groin dissection; and early in the series one case of biopsy and radiation therapy followed 4 years later with a wide local excision. Photodynamic therapy [5] and chemotherapy, neither local nor systemic were used in this series. Surgical treatment trends did not change over time. Positive tumour specimen margins occurred in five (20\%), with 20
(80\%) clear margins and four where there is no record in the QCGC data or in the pathology report. Groin lymph nodes were sampled in one case with all lymph nodes being negative for malignancy. Eight cases had another malignancy (one each for breast, cervical, cervical and endometrial, endometrial, renal, skin, lung, BCC skin). Of 25 cases where QCGC data on specimen margin status and being health is known, 20 had clear specimen margins and 13 are alive without evidence of disease and five died of other diseases (Table 3). Of the five cases with positive margins two underwent further excision and two are undergoing regular follow up checks but one 
Table 3. Patient status versus specimen margin.

\begin{tabular}{cccc}
\hline \multirow{2}{*}{ Status } & \multicolumn{3}{c}{ Specimen margin } \\
\cline { 2 - 4 } & Not clear & Clear & Total \\
\hline Alive & 4 & 13 & 17 \\
Dead of other disease & & 5 & 5 \\
Lost to follow up & 1 & 2 & 3 \\
Total & 5 & 20 & 25 \\
\hline
\end{tabular}

case is lost to follow up after two years.

\section{DISCUSSION}

BCC is the most common human malignant neoplasm which mainly occurs on skin areas exposed to sunlight but also in the axillae, groins, buttocks and external genitalia [6]. BCC of the vulva is uncommon with an incidence of 3.2\% (QCGC vulvar cancer registry, a rate similar to other studies $[7,8])$. The mean age at presentation of 69.5 years was similar to other studies [9,10]. As reported by others, the time from the onset of symptoms to diagnosis ranged from a few months to several years [10]. In the Queensland series the average time from symptom to diagnosis was 19.9 months but four cases presented with a two or more year history of vulval symptoms. Lesion size averaged $2.1 \mathrm{~cm}$, the same as reported by others [10] and as previously stated ulceration was present in $50 \%$ cases.

Vulvar biopsy was the final arbiter but on occasions diagnostic difficulty was experienced when there were mixed lesions containing squamous cells and melanomalike pigment which required special histo-chemical techniques to reach a diagnosis [11]. One case of BCC in this series was associated with vulvar lichen sclerosus similar to that reported by Meyrick Thomas et al. [12] and another associated with immunosuppression in a renal transplant patient. Following further attempts at gaining clinical information plus histology and immunohistochemistry reports (rather than report summaries which were coded as BCCs) 21 cases were available for review. This accounts for the eight cases coded as BCC in Tables 1 and 2. Biopsy of groin lymph nodes was rare and the single case in this series where biopsy was undertaken all nodes were free of disease. Treatment was initially surgical in all cases but one who came to wide surgical excision four years after being treated with radiotherapy. We agree with de Giogi et al. [13] that vulvar BCC should be suspected and biopsied whenever lesions thought to be inflammatory in nature do not respond to treatment. The prognosis for vulvar BCC is excellent. Our study showed four of five cases with positive margins were still alive after 17 to 106 months from initial treatment (one lost to follow up after 27 months).

Three cases treated by WLE were referred back to their general practitioners (GP) for follow up without subsequently maintaining contact with the QCGC. This may have been caused by a false sense of security due to the low rate of death from this condition and the age and medical condition of these patients. One case aged 77 years suffered from Alzheimer's disease and was returned to her GP after WLE, another (aged 73 years) after seven months and the third case aged 68 years after two years because she required two re-excisions to achieve negative excision margins. We suggest that all cases of vulvar BCC are registered and followed up via a gynecological oncologist and their data recorded in the gynecological oncology registry. This would reduce the risk of loss to follow up and improve the standard of case records. We recognize the importance of long term follow up irrespective of the status of disease at the margins of surgical specimens as positive findings do not equate to a poor long term outcome.

\section{ACKNOWLEDGEMENTS}

We gratefully acknowledge all those doctors who referred cases to the QCGC and the gynaecological oncologists who have updated QCGC records.

\section{REFERENCES}

[1] Pisani, C., Poggiali, S., De Padova, L., Andreassi, A. and Bilenchi, R. (2006) Basal cell carcinoma of the vulva. Journal of the European Academy of Dermatology and Venereology, 20, 446-448. doi:10.1111/j.1468-3083.2006.01456.x

[2] Feakins, R.M. and Lowe, D.G. (1997) Basal cell carcinoma of the vulva a clinicopathological study of 45 cases. International Journal of Gynecological Pathology, 16, 319324. doi:10.1097/00004347-199710000-00005

[3] Gibson, G.E. and Ahmed, I. (2001) Perianal and genital basal cell carcinoma, a clinicopathologic review of 51 cases. Journal of the American Academy of Dermatology, 45, 68-71. doi:10.1067/mjd.2001.114588

[4] Ridley, C.M. (2009) The vulva. Neill, S. and Lewis, F. Eds., 3rd Edition, Wiley-Blackwell, Oxford, 182.

[5] Brown, S.B., Brown, E.A. and Walker, I. (2004) The present and future role of photodynamic therapy in cancer treatment. The Lancet Oncology, 5, 497-508. doi:10.1016/S1470-2045(04)01529-3

[6] de Giorgi, V., Salvini, C., Massi, D., Raspollini, M.R. and Carli, P. (2005) Vulvar basal cell carcinoma: Retrospective study and review of literature. Gynecologic Oncology, 97, 192-194. doi:10.1016/j.ygyno.2004.12.008

[7] Feakins, R.M. and Lowe, D.G. (1997) Basal cell carcinoma of the vulva a clinicopathological study of 45 cases. International Journal of Gynecological Pathology, 16, 319324. doi:10.1097/00004347-199710000-00005 
[8] Gibson, G.E. and Ahmed, I. (2001) Perianal and genital basal cell carcinoma, a clinicopathologic review of 51 cases. Journal of the American Academy of Dermatology, 45, 68-71. doi:10.1067/mjd.2001.114588

[9] Benedet, J.L., Miller, D.M., Ehlen, T.G. and Bertrand, M.A. (1997) Basal cell carcinoma of the vulva: Clinical features and treatment results in 28 patients. Obstetrics \& Gynecology, 90, 765-768. doi:10.1016/S0029-7844(97)00416-X

[10] de Giorgi, V., Salvini, C., Massi, D., Raspollini, M.R. and Carli, P. (2005) Vulvar basal cell carcinoma: Retrospective study and review of literature. Gynecologic Oncology,
97, 192-194. doi:10.1016/j.ygyno.2004.12.008

[11] Lloyd, J. and Flanagan, A.M. (2000) Mammary and extramammary Paget's disease. Journal of Clinical Pathology, 53, 742-749. doi:10.1136/jcp.53.10.742

[12] Meyrick, T.R.H., McGibbon, D.H. and Munro, D.D. (1985) Basal cell carcinoma of the vulva in association with vulval lichen sclerosus et atrophicus. Journal of Royal Society of Medicine, 78, 16-18.

[13] de Giorgi, V., Salvini, C., Massi, D., Raspollini, M.R. and Carli, P. (2005) Vulvar basal cell carcinoma: Retrospective study and review of literature. Gynecologic Oncology, 97, 192-194. doi:10.1016/j.ygyno.2004.12.008 